\title{
Anémonas, corales y medusas: los cnidarios y su importancia médica
}

\author{
José Fernando Lazcano Pérez, Zayil Salazar Campos y \\ Humberto González-Márquez
}

\section{Resumen}

Los cnidarios son probablemente los organismos más bellos y excéntricos del océano. Desde hace millones de años, habitan todos los mares de la Tierra a diferentes profundidades y latitudes. Pero debido a que son venenosos y que el entrar en contacto con ellos puede producir ardor y dolor por un tiempo, pocas especies han sido consideradas de importancia médica para el ser humano.

Al igual que con otros animales venenosos, los científicos han estudiado sus toxinas para saber cómo funcionan y si podemos utilizarlas como agentes terapéuticos. Actualmente, existen trabajos de investigación que demuestran los efectos farmacológicos de algunas sustancias extraídas de su veneno, tales como combatir enfermedades virales, autoinmunes e, incluso, la gastritis. Por lo tanto, debemos luchar por la conservación de estos organismos no sólo debido a su potencial farmacológico, sino porque la gran mayoría se encuentran severamente amenazadas y representan la base de los ecosistemas marinos más biodiversos.

Palabras clave: cnidarios, veneno, toxinas, canales iónicos, terapéuticos.

\section{ANEMONES, CORALS AND JELLYFISHES: CNIDARIANS AND ITS MEDICAL IMPORTANCE}

\begin{abstract}
Cnidarians are considered the most beautiful and eccentric organisms in the ocean. They have inhabited Earth's seas for millions of years at many depths and latitudes. However, since they are venomous and contact with them might produce pain and burning sensation for a while, just a few species have been considered of medical importance for humans.

As with other venomous species, cnidarian toxins are studied in order to know their mechanisms of action and to find new therapeutic agents. Many research works describe some cnidarian compounds that have pharmacological properties against viral and autoimmune diseases, and even gastritis. Even more important, since many of this species are severely endangered, it is important to fight for its conservation, not only due to its pharmacological potential, but also because some species are the basis for marine ecosystems with greatest diversity.
\end{abstract}

Keywords: cnidarians, venom, toxins, ion channels, therapeutics.

Dol: http://doi.org/10.22201/codeic.16076079e.2020.v21n2.a4 
Se tituló como Químico en la Universidad Autónoma del Estado de México y obtuvo el grado de Doctor en Ciencias en la Universidad Nacional Autónoma de México (UNAM). Su interés principal se centra en el estudio de toxinas de origen animal, particularmente de cnidarios. Ha sido autor y coautor de artículos en revistas nacionales e internacionales. Es miembro del sNı, nivel ı. Actualmente es investigador posdoctoral en la Unidad Académica de Sistemas Arrecifales Puerto Morelos del Instituto de Ciencias del Mar y Limnología de la UnAm y es profesor en la materia "Métodos de identificación, purificación y caracterización de toxinas marinas" del Posgrado en Ciencias del Mar y Limnología de la UnAM.

\section{Zayil Salazar Campos}

zayil.salazar@gmail.com

Bióloga con Maestría en Biología Celular por la Facultad de Ciencias de la unam y Doctorado en Biología Experimental por la UAM-I. Ha sido coautora en libros de texto para nivel medio y medio superior. Ha trabajado como profesora de tiempo completo en la uam y ha participado en la publicación de artículos científicos y de divulgación. Actualmente se desempeña como profesora de asignatura de la Facultad de Ingeniería de la UNAM.

\section{Humberto González-Márquez}

hgm@xanum.uam.mx

Estudió biología, con área de concentración en Biología Experimental y Maestría en Biología Experimental, en la UAm. Preparó y sostuvo su Tesis Doctoral en Ciencias, mención Bioquímica, en la universidad Henry Poincaré, de Nancy, Francia. Ha trabajado en la uAm desde 1985. Actualmente es Profesor Investigador Titular C y miembro del Sistema Nacional de Investigadores, nivel ı. Ha publicado 33 artículos en revistas internacionales, 3 capítulos de libros, así como 6 artículos de divulgación, Ha presentado sus trabajos en múltiples congresos y reuniones especializadas tanto nacionales como extranjeras. Sus líneas de investigación versan sobre la purificación de proteínas y el análisis proteómico, con el fin de buscar biomarcadores y proteínas con actividad biológica. Asimismo, está interesado en el estudio la fisiología espermática, sobre todo en la capacitación. 


\section{Introducción}

En 1901, el príncipe Alberto । de Mónaco, un apasionado estudioso del mar y fundador del Museo Oceanográfico de Mónaco, organizó un crucero científico a bordo del barco Princesa Alicia ॥, al cual invitó a dos importantes científicos franceses, Paul Portier y Charles Robert Richet (Dworetzky, et al., 2002). Su objetivo era estudiar el contacto con los tentáculos de la fragata portuguesa, un organismo marino venenoso, para saber cómo causaba tanto dolor, parálisis, así como otros efectos patológicos en bañistas y buzos, que representaban un gran problema médico y afectaba el turismo de la zona.

Robert Richet se sintió bastante entusiasmado con el proyecto al que fue invitado por su afición al estudio de los venenos. Él aseguraba que, al igual que las vacunas de Pasteur, la inyección de pequeñas y repetidas dosis del veneno en perros y conejos podría generar inmunidad. Durante sus experimentos descubrió que al inyectar en sus perros una pequeña dosis no letal, ésta podía no tener ningún efecto o, si acaso, una comezón ligera y dificultad para respirar; pero que si pasado algún tiempo, alrededor de tres semanas después, les ponía una dosis aún menor, todos morían después de haber sufrido diversos síntomas. A este fenómeno se le dio el nombre de anafilaxia y después de diez años de intenso trabajo, el 11 de diciembre de 1913, Richet fue galardonado con el Premio Nobel de Medicina. Sus resultados fueron el primer paso para el análisis de los venenos de unos organismos muy peculiares llamados cnidarios, que habitan en todos los mares del planeta.

Imagen 1. Algunos cnidarios representativos. A) Cassiopea xamachana o medusa invertida (7 cm), foto: Paolo Urbano Del Águila. B) Acropora palmata (un coral). D) Bunodosoma cavernatum, una anémona verdadera, compartiendo roca con una colonia de $4 \mathrm{~cm}$ de Zoanthus sociatus (zoantideo), foto: Francisco Ibarra Canales.

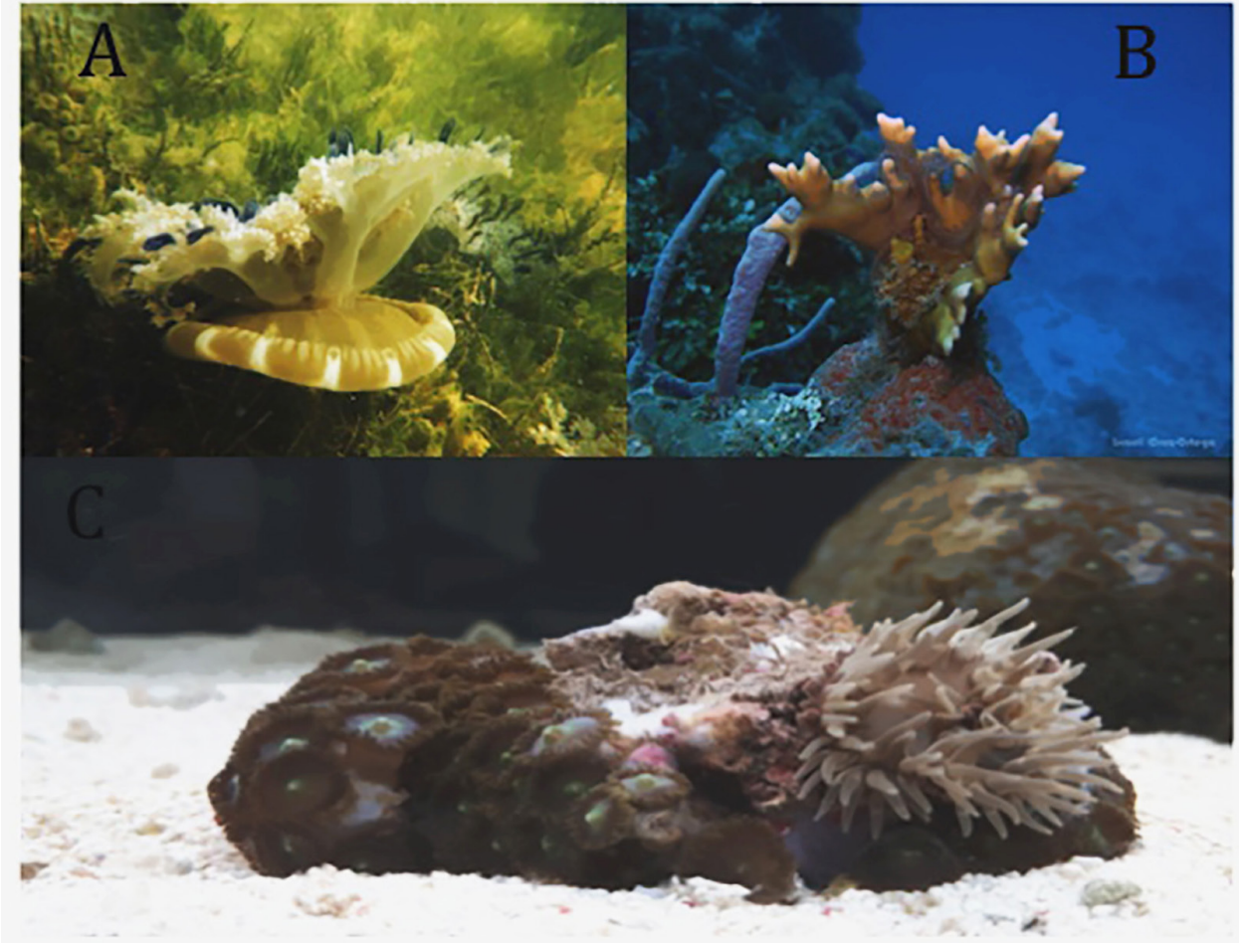


Imagen 2. Los nematocistos son considerados las estructuras venenosas más complejas de la naturaleza. Su descarga es tan potente que puede penetrar profundamente la piel de una presa en menos de tres milisegundos, e inyectar el veneno para paralizar y matar en minutos o hasta en segundos. Escala $=20 \mu \mathrm{m}$. Foto: Dr. Ricardo González Muñoz.

1 Un filo es una "Categoría taxonómica fundamental de la clasificación biológica, que agrupa a los organismos de ascendencia común y que responden a un mismo modelo de organización" (Real Academia Española, 2019).
La clasificación o filo ${ }^{1}$ Cnidaria es un grupo de animales que comprende organismos acuáticos (en su mayoría marinos) de cuerpo gelatinoso, tentaculados, principalmente carnívoros. Poseen una estructura muy simple con simetría radial, es decir, una distribución equilibrada del cuerpo alrededor de un eje central. Algunos investigadores consideran que aparecieron hace aproximadamente 1,000 millones de años, convirtiéndose en el segundo grupo más antiguo del reino animal, después de las esponjas. Existen casi 11,000 especies diferentes (Collins, 2009) y quizá se traten de los organismos más coloridos y excéntricos del ambiente marino (ver imagen 1).

Dentro de este grupo podemos encontrar a las medusas, anémonas, corales, zoantideos, abanicos de mar, entre otros. Todos poseen tentáculos u otras estructuras cubiertas de células llamadas cnidocitos (de ahí el nombre cnidario que significa ortiga en griego), que secretan unos orgánulos urticantes muy curiosos llamados cnidocistos.

Los cnidocistos se clasifican en tres tipos: los nematocistos, presentes en todos los cnidarios; los espirocistos, sólo en los clasificados como Anthozoa; y los pticocistos, que pertenecen únicamente a los animales de la subclase Ceriantharia, nombrados también anémonas tubícolas. Los nematocistos son dispositivos en forma de cápsula con una especie de arpón que se dispara al tocar a una presa o depredador y penetra en él inyectando veneno (ver imagen 2). Todos los cnidarios poseen nematocistos y es lo que distingue al filo Cnidaria de todos los demás (Fautin, 2009).

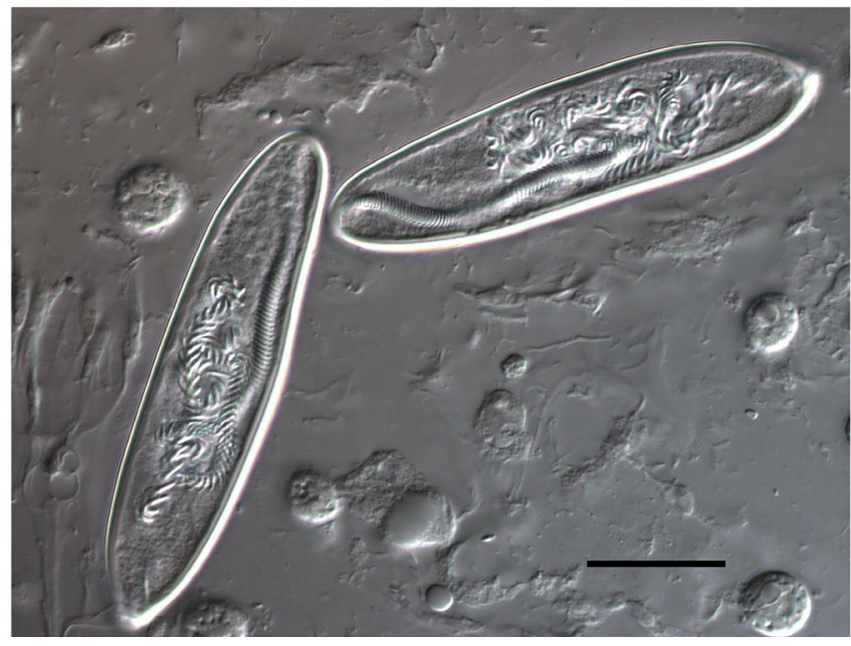

Dentro de los nematocistos se produce y almacena el veneno, una mezcla compleja de sustancias de naturaleza química muy variada, tales como péptidos, proteínas, fosfolipasas (enzimas capaces de degradar los fosfolípidos de las membranas de las células), glicoproteínas, esteroles, carbohidratos y aminas bioactivas, como la histamina y la serotonina. Ya que casi todos los cnidarios son venosos, representan una fuente muy amplia para el estudio de las toxinas de animales. 
Imagen 3. Estructura química de la palitoxina, una de las toxinas más potentes que se conocen y que fue descubierta en zoantideos del género Palythoa. Actualmente sabemos que la producen dinoflagelados simbiontes del género Ostreopsis.
El contacto con los tentáculos de los cnidarios puede afectar, primero, a la piel produciendo edema, necrosis, dermatitis y urticaria. Posteriormente, el veneno viaja a través del sistema linfático y los vasos capilares, y puede afectar el corazón o el sistema nervioso central. En casos muy severos genera un dolor muy intenso, neuropatías, parálisis, dificultad respiratoria, síntomas oftalmológicos, mononeuritis múltiple y, en ocasiones, puede causar la muerte.

Los cnidarios también tienen la capacidad de almacenar sustancias tóxicas que no son producidas por ellos, sino por organismos con los que viven en simbiosis, una relación que les beneficia mutuamente. Tal vez el caso más conocido sea el de la palitoxina, la segunda toxina no proteínica más potente que se conoce en la Tierra, descubierta en 1971 en un tipo de cnidarios del orden Zoantidea (clase Anthozoa, género Palythoa). Su estructura química es tan complicada que no fue sino hasta once años después que se pudo elucidar (ver imagen 3). Los zoantideos son animales muy valiosos para los aficionados a los acuarios marinos, no en vano se reportan muchos casos de envenenamiento por contacto con ellos en la literatura médica.
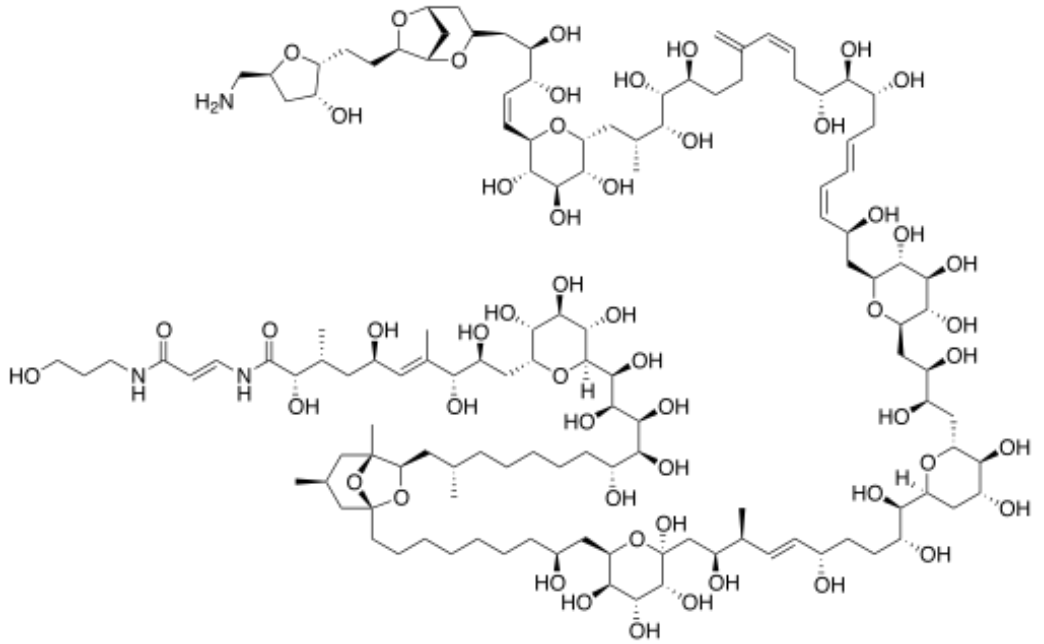

\section{¿Cómo se alimentan los cnidarios?}

Los cnidarios son animales principalmente carnívoros, aunque también pueden ser considerados polífagos oportunistas, es decir, con ayuda de sus tentáculos atrapan crustáceos y peces, a los que les inyectan un veneno, paralizándolos al instante para luego llevarlos a su cavidad oral en donde secretan enzimas que inician el proceso de digestión. Sin embargo, muchos cnidarios han evolucionado en simbiosis con organismos unicelulares fotosintéticos llamados dinoflagelados, principalmente del género Symbiodinium. Esta relación provee a los dinoflagelados de un hogar seguro donde no pueden ser depredados, al interior de la epidermis de los cnidarios; a cambio de ello, fotosintetizan y ofrecen otra alternativa de alimentación al cnidario, dándoles los nutrientes necesarios para vivir. 
Muchas medusas, anémonas y zoantideos tienen una asociación simbiótica, pero una de más conocidas y estudiadas es la de los corales. Los arrecifes de coral están formados por una clase de cnidarios llamados "corales escleractinios" (del griego scleros, piedra). Estos animales producen enormes cantidades de carbonato de calcio, que se agregan en los arrecifes de coral, considerados unos de los ecosistemas más ricos del planeta en términos de diversidad biológica. La relación coral-simbionte depende mucho de varios factores como la luz, la profundidad, el pH del agua y la temperatura del mar. Por ello, el calentamiento global ha afectado seriamente estos ecosistemas en todo el mundo, el aumento de la temperatura del agua ocasiona que los corales expulsen a los simbiontes de sus tejidos, quedándose sin alimento y ocasionando que mueran.

\section{¿Cómo actúa el veneno de los cnidarios?}

Como ya hemos mencionado, el veneno de estos animales consiste en una mezcla de varias sustancias con propiedades diferentes, de forma que cada una afecta de cierta manera al organismo y, en conjunto, logran intoxicar a la presa o depredador. Entre estas sustancias se encuentran comúnmente unas proteínas llamadas fosfolipasas, las cuales destruyen los lípidos de las membranas celulares de los primeros tejidos con los que entra en contacto el veneno, lo que abre paso a las neurotoxinas. Estas proteínas, más pequeñas que las fosfolipasas, dañan a otras moléculas insertadas en las membranas de las células, en este caso nerviosas, conocidas como canales iónicos.

A su vez, en todos los organismos los canales iónicos son proteínas que atraviesan la membrana de algunas células y contienen poros llenos de agua que permiten el flujo de iones a través de ellas. Según la forma en la que se activan pueden ser: a) regulados por voltaje, es decir, requieren cambios en la polaridad de le membrana para activarse; b) activados por un ligando, que se abren o cierran cuando una molécula específica se une a ellos; o c) mecanosensibles, se activan por la acción de un estímulo mecánico.

Dichos canales participan en procesos fundamentales como la transmisión de las señales nerviosas, la secreción de hormonas y neurotransmisores, la regulación de la presión sanguínea, entre otros (Martínez-Rosas, 2004). Además, conducen iones de sodio $\left(\mathrm{Na}^{+}\right)$, potasio $\left(\mathrm{K}^{+}\right)$y calcio $\left(\mathrm{Ca}^{2+}\right)$. Cuando las neurotoxinas del veneno entran en contacto con los canales iónicos, los bloquean o provocan su activación prolongada. Esto significa que pueden impedir completamente el paso de ciertos iones u causar su entrada sin control en momentos cruciales para la célula. Las consecuencias pueden ser fatales, pues las señales nerviosas no llegan a los músculos, generando una parálisis que puede llevar a un paro respiratorio y/o daños en el corazón.

Son precisamente estas actividades biológicas, como romper células o interrumpir la entrada y salida de iones, lo que hace interesante el estudio de los 
componentes en el veneno de los cnidarios, puesto que si logramos controlar su efecto encontraremos la oportunidad de utilizarlas para combatir ciertos padecimientos.

\section{Propiedades farmacológicas}

Comparadas con las de los animales terrestres, como los escorpiones, arañas y serpientes, las sustancias que producen los cnidarios han sido poco estudiadas debido a la dificultad que representa recolectarlos y extraer sus toxinas. Las serpientes o las tarántulas pueden ordeñarse de forma relativamente fácil y es posible obtener una cantidad de veneno suficiente para su análisis. Esto es imposible con los cnidarios, lo cual ha limitado la investigación farmacológica con compuestos derivados de ellos. No obstante, existen varios estudios que han descubierto sustancias con aplicaciones farmacológicas de las que hablaremos brevemente. Comenzaremos por aquellas que presentan la actividad biológica más variada.

De todas las especies de cnidarios que se conocen hasta ahora, los corales blandos (clase Anthozoa, subclase Octocorallia, orden Alcyonacea) han sido la fuente de compuestos más diversa y relevante. Se les denomina así porque, a diferencia de los corales duros, no generan un esqueleto de carbonato de calcio, por tanto, no pueden formar arrecifes, aunque sí habitan en ellos (ver imagen 4). A partir de los corales blandos se han aislado terpenoides, compuestos con características antiinflamatorias, antitumorales, anti-virus de inmunodeficiencia humana (VIH), antimaláricas, antituberculosas y contra úlcera gástrica (Rocha et al., 2011).

Imagen 4. Corales blandos. Se les denomina así porque no producen un esqueleto calcáreo y no pueden formar arrecifes, sin embargo, son parte importante de estos. En la imagen podemos apreciar un abanico de mar (gorgonáceo), que puede medir hasta $60 \mathrm{~cm}$, organismos de los cuales se han aislado compuestos con actividad biológica importante contra varias enfermedades como el cáncer o la infección por VIH (foto: Dr. Israel Cruz Ortega).

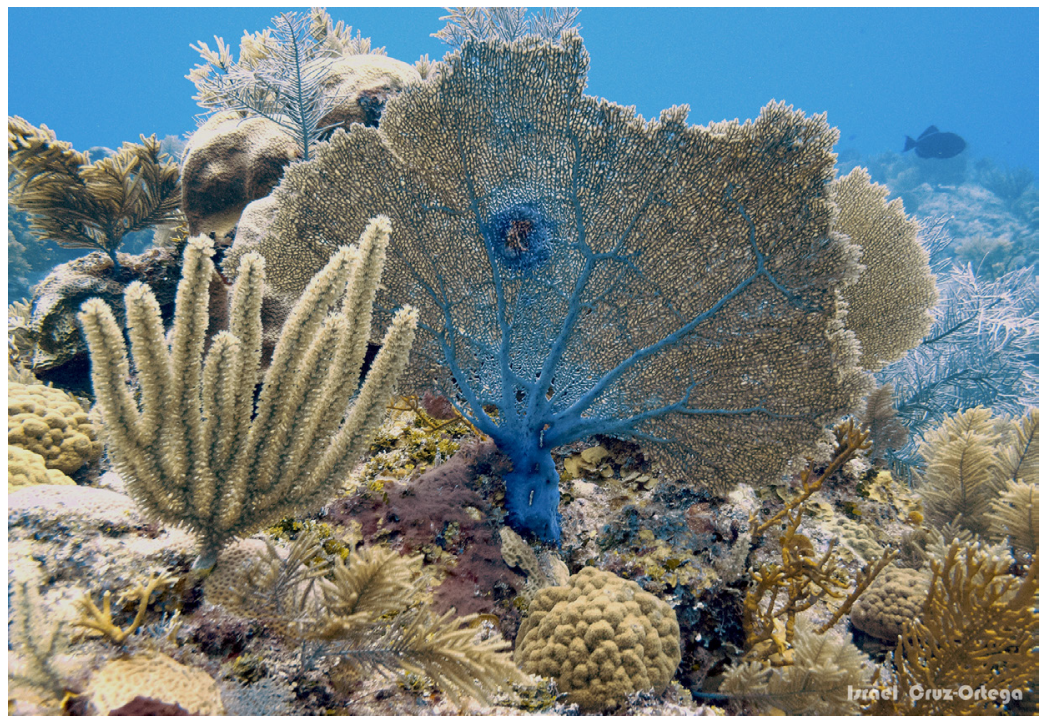

Sustancias con actividad antiinflamatoria como la pseudopterosina, la eleutherobina y la sarcodictina ya están en fase preclínica y podrían ser utilizadas como antipiréticos (capaces de bajar la fiebre) (Mariottini, G.L., 2017). 
Imagen 5. A) Palythoa caribaeorum, un zoantideo muy abundante en arrecifes mexicanos (foto: Dr. Ricardo González Muñoz). Las colonias alcanzan extensiones de varios metros cuadrados en un arrecife. B) Estructura química de una neurotoxina, aislada de $P$. caribaeorum, que afecta canales de sodio en neuronas de rata.
Por otro lado, hay una mayor la variedad de compuestos terpénicos, los cuales tienen actividad contra líneas celulares cancerosas, como cáncer de mama y de pulmón. En algunos corales blandos y en medusas (clase Scyphozoa) también se han localizado sustancias que bloquean la entrada del VIH a las células T, proporcionando una nueva fuente de antirretrovirales.

Otro grupo de cnidarios ampliamente estudiado son las anémonas (Lazcano-Pérez et al., 2016). Sabemos que sintetizan péptidos de bajo peso molecular, que afectan sobre todo los canales iónicos de sodio y de potasio regulados por voltaje, pero recientemente se descubrió que, de igual modo, podrían afectar los canales de calcio (Lazcano-Pérez et al., 2016). Todos estos péptidos son toxinas letales cuando se administran a insectos, crustáceos o ciertos mamíferos como los ratones (ver imagen 5). Sin embargo, modificadas químicamente o en dosis adecuadas pueden emplearse con propósitos médicos. Por ejemplo, una toxina aislada de la anémona Stichodactyla helianthus bloquea los canales iónicos permeables a potasio KV1.3, implicados en la activación y proliferación de los linfocitos T humanos. Si mediante esta toxina es viable bloquear a estos linfocitos, entonces, se podría aprovechar para combatir enfermedades autoinmunes, por lo que ahora se encuentra en fase clínica para tratar la esclerosis múltiple (Chi et al., 2011).

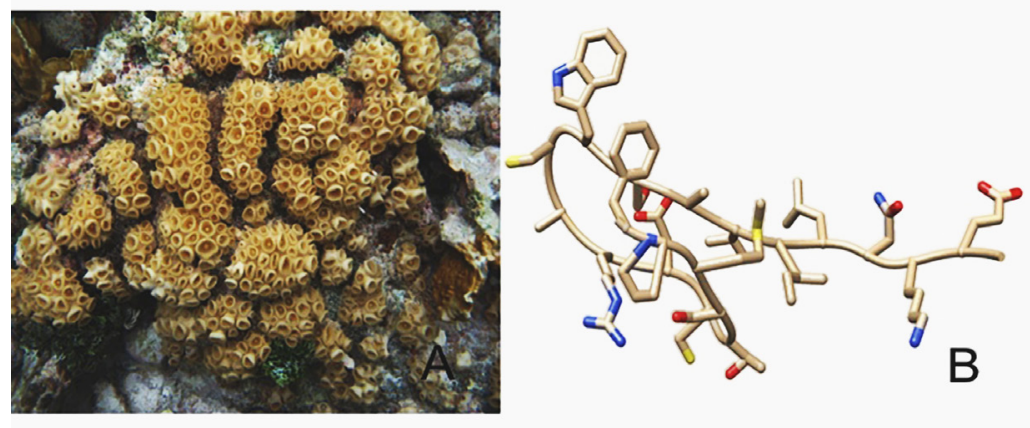

Ya que los canales iónicos están implicados en muchos procesos fisiológicos, así como en enfermedades y padecimientos como la leucemia, la esclerosis múltiple, la obesidad o hasta la infertilidad, resulta factible decir que, al encontrar la molécula adecuada para regularlos, se avanzará en el diseño de nuevos medicamentos para tratar éstas y otras patologías.

\section{¿Qué hacer si nos pica una medusa?}

Hay una muy baja probabilidad de que una persona se encuentre con una anémona o un coral, poca gente incursiona en los arrecifes. Aunque sí ocurren muchos casos de turistas que han tenido malos ratos al tocar los hermosos corales de fuego y las anémonas, para satisfacer su curiosidad. Asimismo, estos animales son organismos sésiles, crecen adheridos a un sustrato y nunca se desplazan, se refugian entre las rocas y pueden pasar desapercibidos. 
Por otro lado, toparse con una medusa sucede frecuentemente, debido a que nadan en las mismas zonas que los turistas. Los cnidarios más populares por sus efectos nocivos sobre las personas son las medusas conocidas como aguamalas. Estas criaturas suelen rondar las playas, principalmente durante el verano, y el simple roce con sus tentáculos produce enrojecimiento en la piel, comezón y ardor intenso. Como muchas son transparentes, resulta casi imposible verlas mientras nadamos; sólo hasta que sentimos el ardor y vemos la dermatitis en la zona de contacto nos daremos cuenta que fuimos tocados por una. Existe la creencia de que al orinar sobre la zona dañada estos efectos disminuyen, mas esto aún no está comprobado. Lo que sí sabemos es que aplicar vinagre y después enjuagarse con agua de mar inactiva los nematocistos que no han sido descargados sobre la piel. Rara vez anticipamos picaduras de medusas, por lo que no es común contar con una botella de vinagre; en ese caso, el refresco de cola puede servir por su bajo pH. Tampoco se recomienda lavar la zona afectada con agua dulce antes de haber realizado el enjuague con agua marina, dado que el agua corriente puede activar los nematocistos que continúan adheridos a la piel. Los síntomas leves terminan después de varios minutos y si persisten, se puede utilizar una crema con hidrocortisona.

En México, no hay especies de medusas que impliquen un riesgo grave para la salud; sin embargo, en Australia y el sureste de Asia habitan especies que sí lo representan. Por ejemplo, la Avispa de mar (Chironex fleckeri), una medusa que abunda durante el verano en el norte de Australia, y que es considerada el animal más venenoso del mundo, puede matar a una persona en cuestión de minutos. También, el contacto con otras medusas produce el llamado "Síndrome Irukandji", el cual consiste en síntomas muy severos como dolor fuerte en la espalda baja, calambres intensos en las extremidades, abdomen y pecho, sudoración, ansiedad, náusea, vómito, dolor de cabeza, hipertensión, edema pulmonar, etcétera, y en los casos más severos puede producir la muerte.

Debe señalarse que las medusas no son agresivas. Lo más probable es que ni siquiera les importe que estemos ahí, por tanto, si vemos una nadando cerca de nosotros, lo mejor será alejarnos de ella y evitarla, seguramente no tendrá ninguna intención de perseguirnos.

\section{Conclusiones}

No cabe duda que los cnidarios forman parte de los animales más curiosos y fascinantes del mar. Posiblemente la mayoría de los que hemos ido a la playa hemos tenido algún contacto con medusas o corales, desde simplemente observarlos, hasta haberlos tocado a propósito o accidentalmente, de forma que quizá hemos experimentado las dolorosas consecuencias. Aun así, no dejan de ser animales fascinantes y en los últimos años se ha vislumbrado que podrían ser la fuente de sustancias con propiedades terapéuticas novedosas como lo han sido muchos otros organismos venenosos. Aunado a esto, su estudio y 
conservación tienen una vital importancia, ya que los arrecifes coralinos son uno de los ecosistemas más diversos del planeta y están severamente amenazados por la acción del hombre.

\section{Referencias}

- Charlesy. (2016). Palytoxin [imagen]. Recuperado de https://en.wikipedia.org/wiki/ Palytoxin.

* Chi, V., Pennington, M. W., Norton, R. S., Tarcha, E. J., Londono, L. M., Sims-Fahey, B., Upadhyay S.K., Lakey J.T., ladonato S., Wulff H., Chandy K.G. \& Beeton, C. (2012). Development of a sea anemone toxin as an immunomodulator for therapy of autoimmune diseases. Toxicon, 59(4), 529-546. Dol: https://doi.org/10.1016/j. toxicon.2011.07.016.

* Collins, A. G. (2009). Recent insights into cnidarian phylogeny. Smithsonian contributions to the marine sciences, 38, 139-143.

* Dworetzky, M., Cohen, S., Cohen, S. G., \& Zelaya-Quesada, M. (2002). Portier, Richet, and the discovery of anaphylaxis: a centennial. Journal of Allergy and Clinical Immunology, 110(2), 331. Dol: https://doi.org/10.1016/S0091-6749(02)70118-8.

* Fautin, D. G. (2009). Structural diversity, systematics, and evolution of cnidae. Toxicon, 54(8), 1054-1064. Dol: https://doi.org/10.1016/j.toxicon.2009.02.024.

- Lazcano-Pérez, F., Castro, H., Arenas, I., García, D. E., González-Muñoz, R., \& Arreguín-Espinosa, R. (2016). Activity of Palythoa caribaeorum Venom on VoltageGated Ion Channels in Mammalian Superior Cervical Ganglion Neurons. Toxins, 8(5), 135. Dol: https://doi.org/10.3390/toxins8050135.

* Lazcano-Pérez, F., Hernández-Guzmán, U., Sánchez-Rodríguez, J., \& ArreguínEspinosa, R. (2016). Cnidarian neurotoxic peptides affecting central nervous system targets. Central Nervous System Agents in Medicinal Chemistry (Formerly Current Medicinal Chemistry-Central Nervous System Agents), 16(3), 173-182. Dol: https://doi.org/10.2174/1871524915666150722120915.

* Real Academia Española (2019). Filo. En Diccionario de la lengua española [23. a ed., versión 23.3 en línea]. Real Academia Española. Recuperado de: https://dle.rae.es.

* Rosas, M. M. (2004). Los canales iónicos: la biología y patología. Archivos de cardiología de México, 74(s2), 205-210. Recuperado de: https://www.medigraphic. com/pdfs/archi/ac-2004/acs0420.pdf.

\section{Cómo citar este artículo}

* Lazcano Pérez, José Fernando, Salazar Campos, Zayli y González Márquez, Humberto (2020). Anémonas, corales y medusas: los cnidarios y su importancia médica, Revista Digital Universitaria (RDU). Vol. 21, núm. 2 marzo-abril. Dol: http://doi. org/10.22201/codeic.16076079e.2020.v21n2.a4.

Recepción: 26/09/2018. Aprobación: 14/11/2019 